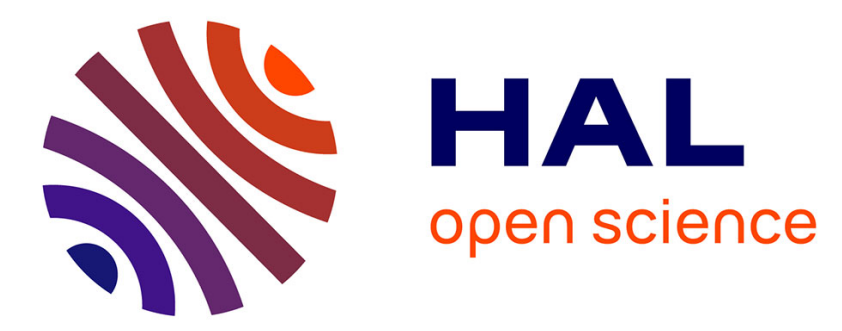

\title{
Excitation of Lower-Hybrid Wave by Beating of Two Electron-Cyclotron Waves
}

\author{
G. Batanov, A. Petrov, L. Kolik, K. Sarksyan, N. Skvortsova
}

\section{To cite this version:}

G. Batanov, A. Petrov, L. Kolik, K. Sarksyan, N. Skvortsova. Excitation of Lower-Hybrid Wave by Beating of Two Electron-Cyclotron Waves. Journal de Physique IV Proceedings, 1995, 05 (C6), pp.C6-97-C6-100. 10.1051/jp4:1995619 . jpa-00253982

\section{HAL Id: jpa-00253982 https://hal.science/jpa-00253982}

Submitted on 1 Jan 1995

HAL is a multi-disciplinary open access archive for the deposit and dissemination of scientific research documents, whether they are published or not. The documents may come from teaching and research institutions in France or abroad, or from public or private research centers.
L'archive ouverte pluridisciplinaire HAL, est destinée au dépôt et à la diffusion de documents scientifiques de niveau recherche, publiés ou non, émanant des établissements d'enseignement et de recherche français ou étrangers, des laboratoires publics ou privés. 


\title{
Excitation of Lower-Hybrid Wave by Beating of Two Electron-Cyclotron Waves
}

G.M. Batanov, A.Ye. Petrov, L.V. Kolik, K.A. Sarksyan and N.N. Skvortsova

General Physics Institute, Russian Academy of Sciences, Vavilova 38, Moscow, 117942, Russia

\begin{abstract}
The first experiment is described on the excitation of lower-hybrid wave by the beating of two extraordinary electron-cyclotron weves. Electron wave frequencies were near $1 \mathrm{GHz}$, the lower-hybrid wave wes in the frequency range 1-3 MHz. The resonance dependence of excitation of the ear wave on the magnetic field was proved.
\end{abstract}

\section{INTRODUCTION}

During the last yoars in plasma physics there is the contimous interest to the problem of induced excitation of plasma waves by the beating of two incident waves / 1-3/. Primary this interest is comected with the excitation of langnuir waves due to the mixing of two laser beams for investigation new efficient methods of electron acceleration / 4 /. Excitation of lower-hybrid waves in a magnetised plasma by beating process mechanism seems rather interesting too. This way of wave excitation may be proposed as a new method for creating lower-hybrid waves widely used for plasma heating and current generation in toroidal devices. For the first time, the lower-hybrid wave was created by the beating of two oblique lengmuir waves in 15,6/. The local build-up of the beat lower-hybrid wave was accompanied by the electron heating with maxwellization of the electron velocity distribution finction. In this article, we present the first results on the observation of the lower-hybrid wave excited by the beating of two electron-cyclotron waves.

\section{EXPERIMENTAL TECHNIQUES AND APPARATUS}

The experiment was carried on in a model linear device TAU-1 /7/. The plasma was produced by the electron beam ( $\mathrm{U}_{b}=-50 \mathrm{~V}--150 \mathrm{~V}, \mathrm{I}_{b}=50-150 \mathrm{~mA}$ ). We used argon as a working gas at pressure of 3*10 torr, the intensity of the magnetic field was $\mathrm{H}=0.4-0.6 \mathrm{~T}$. Plasma density on the axis $-\mathrm{n}_{8}(0)=$ $7^{*} 10^{9}-4^{*} 10^{10} \mathrm{~cm}^{-3}$, electron temperature $-T_{0}(0)=5-7 \mathrm{eV}$, ion temperature $-T_{i}(0)=0.1 T_{0}(0)$.

Two olectron-cyclotron waves were excited in plasma by means of two pairs of loop antemas. The angle between the antennas in the pair was $90^{\circ}$. High frequency signals were gent from two magnetrons through ferrite rectifiers onto antennas. Magnetron frequencies were close to $1.8 \mathrm{GHz}$. The resonance 
condition ( $\omega=\omega_{H_{e}}$ ) was satisfied in a field $H=0.64 T$. The phase shift between the waves from different antemas in pairs was $\pi / 4$ because of different cable lengths. As a result, the extraordinary electroncyclotron waves were excited in plasma. Two $1 \mathrm{~kW}$-magnetrons operated in step; the pulse duration varied from 1 to $13 \mathrm{~ms}$. The difference in the frequency between the magnetrons could be changed in the range of 1-3 MHz, that corresponds to lower-hybrid range of plasma waves. Plasma frequency ratio in the experiment was the following: $\omega_{8}<\omega_{L_{1}} \sim \omega_{L H}<\omega_{01}, \omega_{02}<\omega_{L \text {, }}, \omega_{\mathrm{Ht}}$, where $\omega_{\mathrm{He}}$ is the electron byrofrequency; $\omega_{s,} \omega_{L H}$ are ion-sound, lower-hybrid frequencies; $\omega_{h i s} \omega_{2,}$ are ion and olectron langmuir frequencies, respectively.

We used the probe technique to measure the main plasma parameters and the low-frequency fluctuations of plasma density. The averaged low-frequency spectra were obtained by using a fast Fourier transform routine with the preliminary choice of appropriate window and numerical filtration. The high-frequency spectra were measured by the loop probes and the spectrum analyser.

\section{EXPERIMENTAL OBSERVATIONS}

The high-frequency spectrum of two extraordinary electron-cyclotron waves is shown in Fig.1. The magnetic field differs from resonance value for these waves by $2 \%$. The amplitude of waves decreases when the magnetic field approaches the resonance value, while the absorption of these waver in plasma increases.

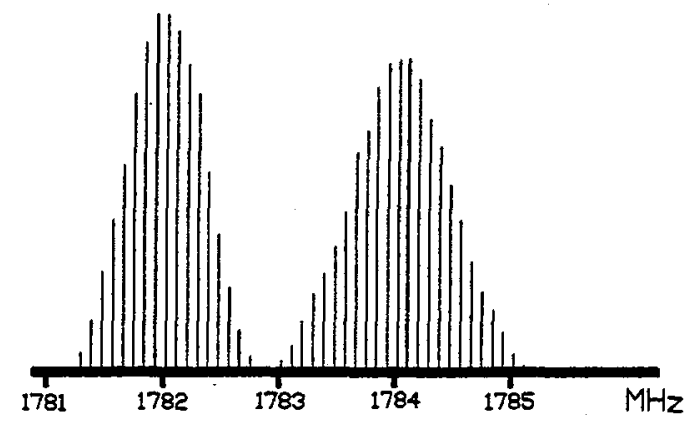

Fig.1. Spectra of two electron-cyclotron waves, excited in plasma near resonance value of magnetic field.

We observed the arising of the low-frequency beat wave in the pump field of two electron-cyclotron waves. The frequency of this wave is the same as the frequency shift between two high-frequency waves, i.e. is the frequency of lower-hybrid plasma wave. The intensity of this wave depends on the magnetic field value for the beat wave is plotted against the value of the magnetic field for two plasma densities (Fig. 2): $7^{*} 10^{9} \mathrm{~cm}^{-3}(\mathrm{a})$ and $3^{*} 10^{16} \mathrm{~cm}^{-3}(\mathrm{~b})$. The difference in frequency between two magnetrons was 2 $\mathrm{MHz}$ There are two peaks in the curve, that represents excitation of the low-frequency wave. Two peaks in the curve are displaced with respect to the resonance value of the magnetic field. The amplitude of the two low frequency wave produced by beating of two electron-cyclotron waves depends on the intensity of the pump waves and conditions of lower-hybrid wave excitation. The amplitude of pump waves is defined by two factors: the dispersion relation of extraordinary electron-cyclotron waves and condition of the 
wave propagation in the beyond-cuttoff wayeguide filled with plasma. Interaction of all these factors completely defined the curves in Fig. 2.

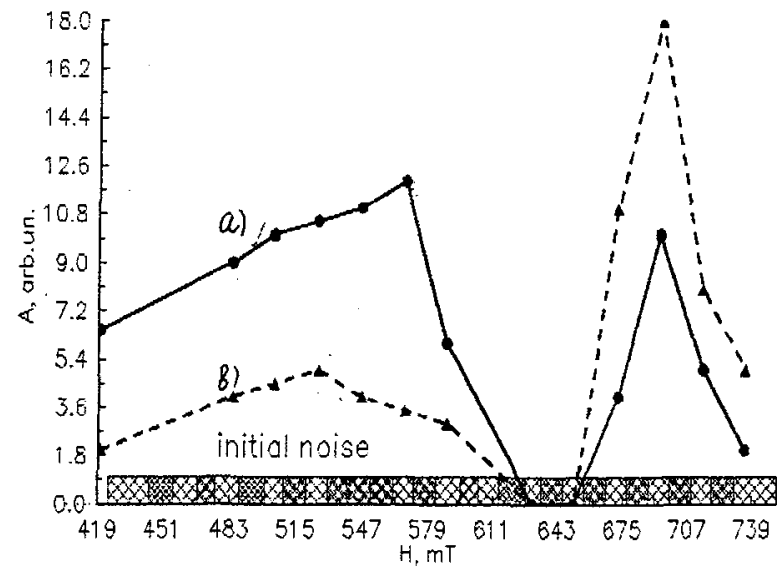

Fig. 2. Dependence of the beat wave amplitude on the magnetic field value for two plasma densities: $7 * 10^{9} \mathrm{~cm}^{-3}$ (a) and $3^{*} 10^{10} \mathrm{~cm}^{-3}(\mathrm{~b})$. The difference in frequency between magnetrons is $2 \mathrm{MHz}$.

For example, in the cyclotron resonance case no lower-hybrid wave is observed becanse of the full absorption of electron-cyclotron waves. The difference between maximum peaks for two plasma densities ( $H>$ Hres and $H<H r e s$ ) is determined first of all by difference beyond-cutoff conditions for pump electron-cyclotron waves. The dependence of the beat wave excitation of plasma density in defined plasma density region is the same as for the previous experiments with the excitation of lower-hybrid wave by two oblique langmuir waves.

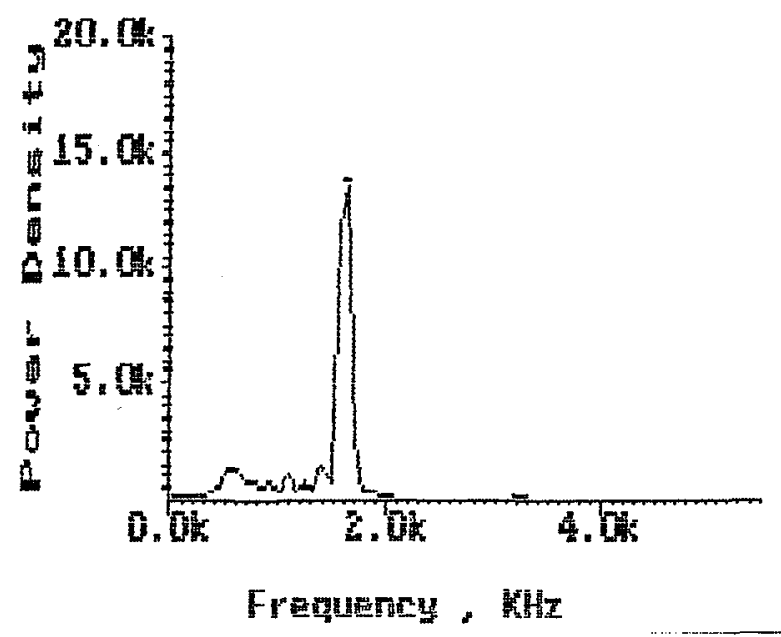

Fig.3. Averaged ( 8 realizations ) low-frequency spectra for plasma donsity $7^{*} 10^{\circ} \mathrm{cm}^{-3}$ in maximum of beat wave excitation. The difference in frequency between magnetrons $1.5 \mathrm{MHz}$. 
The averaged low-frequency spectra of lower-hybrid wave excited by the beating and corresponded to peak in Fig. 2 for magnetic field less then resonance value is shown in Fig.3.

\section{CONCLUSIONS}

In this issue the first experiment is described on the excitation of lower-hybrid wave by the beating of two extraordinary electron-cyclotron waves. Electron wave frequencies were near $1 \mathrm{GHz}$, the loworhybrid wave was in the frequency range 1-3 $\mathrm{MHz}$. The resonance dependence of excitation of the beat wave on the magnetic field and plasma density was proved.

This work was also supported by the Russian Foundation for Fundamental Research, grant N 94-0203504

\section{REFERENCES.}

1. Kroll et al. Phys. Rev. Lett. 13(1964) 83-93.

2. Tang C.M. Appl.Phys. Latt. 45 (1984) 375-377.

3. Porsland D.W. et al. Phys.Rev.Lett 54(1985),558-562.

4. Fainberg Ya.B. Plasma physics. 13(1987) 607-621.

5. Batanov G.M. et al. Plasma physics,17(1991),1026-1031.

6. Batanov G.M.F et al. XXI ICPIG, Bochum, Germary, 3(1993),336-346.

7. Batanov G.M et al. Proc. Lebedev Inst, Moscow, 160(1985),122-134. 